\title{
Comparison of clinical and postmortem diagnosis of pulmonary embolism
}

\author{
B KARWINSKI, E SVENDSEN \\ From the Department of Pathology, The Gade Institute, University of Bergen, Norway
}

SUMMARY The incidence of pulmonary embolism and the number of clinically missed diagnoses of it in necropsies carried out between 1960 and 1984 at this department were investigated. Pulmonary embolism primarily affects elderly people with serious underlying disease; in this study it was found more often in women. The incidence of pulmonary embolism ( $9 \%$ of all necropsies) was unchanged during the period studied. In contrast, pulmonary embolism as the "sole" cause of death increased ( $p$ $<0.0005)$. Although most pulmonary emboli were the immediate cause of death, the clinical diagnosis was often missed (in $84 \%$ of all cases). Furthermore, such clinically missed diagnoses increased over the years $(\mathrm{p}<0.005)$, especially in patients with heart disease and cancer.

Without necropsy there will be considerable underdiagnosis of pulmonary embolism, therefore providing a misleading figure in the death statistics for this often fatal disease.

Pulmonary embolism is a common cause of death, ${ }^{1-9}$ but the clinical diagnosis can be extremely difficult, being recognised in $8 \%-70 \%$ of cases seen at necropsy. ${ }^{2410}$ The incidence of pulmonary embolism is only between $5 \%$ and $14 \%$ in retrospective studies based on routine necropsies in general hospitals. ${ }^{389} \mathrm{In}$ prospective studies the incidence reaches $50 \%-$ $64 \% .{ }^{4711}$ Two studies have shown an increase in the incidence of pulmonary embolism in recent years. ${ }^{612}$

In this department we have had a necropsy rate of between $75 \%$ and $80 \%$ for several decades. ${ }^{13}$ (Medicolegal cases are not included.) The tentative clinical diagnosis and a copy of the death certificate accompanies the clinicians' request for a necropsy. Our material was considered to be suitable for a retrospective study of possible changes in the incidence of pulmonary embolism and the incidence of its clinical detection because necropsies are carried out in a uniform manner and the patients come from the same geographical area.

\section{Material and methods}

The following data were retrieved from the necropsy reports for the years between 1960 and 1984: necropsy number, department, sex, age, duration of last admis- sion, underlying disease, immediate cause of death, and other diseases contributing to death.

The underlying diseases registered in cases with pulmonary embolism were: heart disease, which included acute and old myocardial infarction, rheumatic heart disease, valvular stenoses, myocardial hypertrophy with congestive heart failure; stroke, including intracerebral, subarachnoid, sub- or epidural haemorrhage and cerebral infarction; and cancer, including all malignant tumours. Pulmonary embolism was recorded as the sole cause of death if no other underlying disease, such as diabetes, hypertension, the aforementioned diseases, or other serious diseases were suggested, or detected clinically, or found at necropsy, and no surgery had been carried out. The group "other diseases" included mainly infectious disease, surgically treated benign disease, and psychiatric and neurological disorders other than stroke.

We also noted whether the diagnosis of pulmonary embolism was made or suspected clinically, by looking at the final clinical notation cited in the necropsy records, the copy of the clinical death certificate which often accompanied the request for necropsy, or, since 1975 , a special form for additional information sent with the request for necropsy.

The material was divided into three periods (1960 $69,1970-79$, and 1980-84). The incidence and percentage of missed clinical diagnoses of pulmonary embolism were calculated for each period separately 
Table 1 Incidence of pulmonary embolism at necropsy in men and women 1960-84

\begin{tabular}{llcl}
\hline & $\begin{array}{l}\text { Pulmonary } \\
\text { embolism }\end{array}$ & Necropsy & $\%$ \\
\hline Women & 1028 & 9295 & $11 \cdot 1$ \\
Men & 906 & 12234 & $7 \cdot 4$ \\
Total & 1934 & 21529 & $9 \cdot 0$ \\
\hline
\end{tabular}

Women $v$ men $\chi^{2}=71 \cdot 7 ; \mathrm{p}<0.0005$.

for the medical and surgical departments and for all other departments combined. Patients from the chest wards were included in the figures for the medical departments; "other departments" comprised gynaecology and obstetrics, neurology, psychiatry, otorhinolaryngology, paediatrics and dermatology.

The $\chi^{2}$ test with one or two degrees of freedom was used for statistical analysis.

\section{Results}

Altogether, data were obtained from 21529 necropsies among which 1934 cases of pulmonary embolism were found. The incidence was significantly higher in women (table 1). The median age for both sexes was 75 years for women and 71 years for men. Between 1960 69 and 1980-84 there was an increase from 74 to 78 years among women and from 70 to 72 among men. Pulmonary embolism among children dying mainly of circulatory, infectious, or malignant diseases was rare.

The yearly incidence of pulmonary embolism in the three periods was stable at about $9 \%$ for the total series, varying from $6.8 \%$ to $11.9 \%$. A significant drop was seen from 1970-79 to $1980-84$ in cases from the surgical department (table 2), while the incidence remained mainly unchanged in the medical and other departments.

A shift in the basic disease spectrum among patients with pulmonary embolism occurred during these 25 years (table 3). Heart disease showed an insignificant change. Cancer increased significantly, as did pulmonary embolism as the sole cause of death. "Other diseases" decreased. Pulmonary embolism as the sole cause of death also increased in relation to all the necropsies in the series (table 4).

A significant equal drop in the percentage of clinically diagnosed cases of pulmonary embolism was seen in both sexes. The incidence of clinically diagnosed pulmonary embolism showed a considerable drop in the medical departments, while no significant change was seen in the surgical department (table 5). A dramatic drop in the detection of pulmonary embolism was found for the "other departments" for the years $1970-79$ and $1980-84$, but the figures were too small for statistical evaluation. No significant differ-

Table 2 Incidence of cases of pulmonary embolism in medical, surgical, and other departments combined

\begin{tabular}{|c|c|c|c|c|}
\hline Department & $\begin{array}{l}1960-69 \\
n(\%)\end{array}$ & $\begin{array}{l}1970-79 \\
n(\%)\end{array}$ & $\begin{array}{l}1980-84 \\
n(\%)\end{array}$ & $\begin{array}{l}\text { Total } \\
n(\%)\end{array}$ \\
\hline $\begin{array}{l}\text { Medical: } \\
\text { Necropsy (n) } \\
\text { Pulmonary embolism } \\
\text { Range (\%) } \\
\text { Surgical: } \\
\text { Necropsy (n) } \\
\text { Pulmonary embolism } \\
\text { Range (\%) } \\
\text { Others: } \\
\text { Necropsy (n) } \\
\text { Pulmonary embolism } \\
\text { Range (\%) }\end{array}$ & $\begin{array}{l}4398 \\
504(11 \cdot 5) \\
8 \cdot 7-14 \cdot 5 \\
1595 \\
185(11 \cdot 6) \\
3 \cdot 6-17 \cdot 6 \\
2166 \\
65(3 \cdot 0) \\
1.6-5.5\end{array}$ & $\begin{array}{l}4695 \\
577(12 \cdot 3) \\
9 \cdot 4-16 \cdot 9 \\
\\
1286 \\
180(14 \cdot 0) \\
5 \cdot 7-28 \cdot 6 \\
\\
3198 \\
72(2 \cdot 3) \\
1 \cdot 0-3 \cdot 8\end{array}$ & $\begin{array}{l}1947 \\
240(12 \cdot 3) \\
9 \cdot 3-15 \cdot 1 \\
696 \\
56(8 \cdot 0) \\
5 \cdot 7-28 \cdot 6 \\
\\
1548 \\
55(3 \cdot 6) \\
0 \cdot 8-5 \cdot 1\end{array}$ & $\begin{array}{l}11040 \\
1321(12 \cdot 0) \\
8 \cdot 7-16 \cdot 9 \\
\\
3577 \\
421(11 \cdot 8) \\
3 \cdot 6-28 \cdot 6 \\
\\
6912 \\
192(2 \cdot 8) \\
0.8-5 \cdot 5\end{array}$ \\
\hline
\end{tabular}

Surgical department: 70's $v 80$ 's $\chi^{2}=12 \cdot 2 ; \mathrm{p}<0.0005$.

Table 3 Underlying diseases in patients dying of or with pulmonary embolism

\begin{tabular}{|c|c|c|c|c|}
\hline Diseases & $\begin{array}{l}1960-69 \\
n(\%)\end{array}$ & $\begin{array}{l}1970-79 \\
n(\%)\end{array}$ & $\begin{array}{l}1980-84 \\
n(\%)\end{array}$ & $\begin{array}{l}\text { Total } \\
n(\%)\end{array}$ \\
\hline $\begin{array}{l}\text { Heart disease } \\
\text { Stroke } \\
\text { Pulmonary embolism (sole) } \\
\text { Cancer } \\
\text { Other diseases }\end{array}$ & $\begin{array}{l}270(35 \cdot 8) \\
125(16 \cdot 6) \\
14(1 \cdot 9) \\
184(24 \cdot 2) \\
161(21 \cdot 4)\end{array}$ & $\begin{array}{c}259(31 \cdot 2) \\
123(14 \cdot 8) \\
25(3 \cdot 0) \\
258(31 \cdot 1) \\
164(19 \cdot 8)\end{array}$ & $\begin{array}{r}106(30 \cdot 2) \\
42(12 \cdot 0) \\
28(8 \cdot 0) \\
127(36 \cdot 2) \\
48(13 \cdot 7)\end{array}$ & $\begin{array}{c}635(32 \cdot 8) \\
290(15 \cdot 0) \\
67(3 \cdot 5) \\
569(29 \cdot 4) \\
373(19 \cdot 3)\end{array}$ \\
\hline
\end{tabular}

Cancer 60's $v 70$ 's $v$ 80's $\chi^{2}=9.8 ; \mathrm{p}<0.005$.

Pulmonary embolism 60's $v 70$ 's $v 80$ 's $\chi^{2}=25 \cdot 1$; $\mathrm{p}<0.0005$.

Other 60's $v 70$ 's $v 80$ 's $\chi^{2}=6.5 ; \mathrm{p}<0.05$. 
Table 4 Percentage of necropsies in series in which pulmonary embolism was main and sole cause of death

\begin{tabular}{|c|c|c|c|c|}
\hline & $\begin{array}{l}1960-69 \\
n(\%)\end{array}$ & $\begin{array}{l}1970-79 \\
n(\%)\end{array}$ & $\begin{array}{l}1980-84 \\
n(\%)\end{array}$ & $\begin{array}{l}\text { Total } \\
n(\%)\end{array}$ \\
\hline $\begin{array}{l}\text { Necropsies (n) } \\
\text { Pulmonary embolism }\end{array}$ & $\begin{array}{l}8159 \\
14(0 \cdot 17)\end{array}$ & $\begin{array}{l}9179 \\
25(0 \cdot 27)\end{array}$ & $\begin{array}{l}4191 \\
28(0.67)\end{array}$ & $\begin{array}{l}21529 \\
67(0.31)\end{array}$ \\
\hline
\end{tabular}

Pulmonary embolism 60's $v 70$ 's $v$ 80's $\chi^{2}=22 \cdot 58 ; \mathrm{p}<0.0005$.

Table 5 Percentage of clinically diagnosed cases of pulmonary embolism from various departments

\begin{tabular}{|c|c|c|c|c|}
\hline Departments & $\begin{array}{l}1960-69 \\
n(\%)\end{array}$ & $\begin{array}{l}1970-79 \\
n(\%)\end{array}$ & $\begin{array}{l}1980-84 \\
n(\%)\end{array}$ & $\begin{array}{l}\text { Total } \\
n(\%)\end{array}$ \\
\hline $\begin{array}{l}\text { Medical: } \\
\text { All } \\
\text { Clinical diagnosis }\end{array}$ & $\begin{array}{l}504 \\
98(19 \cdot 4)\end{array}$ & $\begin{array}{l}577 \\
89(15.4)\end{array}$ & $\begin{array}{l}240 \\
25(10 \cdot 4)\end{array}$ & $\begin{array}{l}1321 \\
212(16 \cdot 0)\end{array}$ \\
\hline $\begin{array}{l}\text { Surgical: } \\
\text { All } \\
\text { Clinical diagnosis }\end{array}$ & $\begin{array}{l}185 \\
38(20 \cdot 5)\end{array}$ & $\begin{array}{l}180 \\
32(17 \cdot 8)\end{array}$ & $\begin{array}{l}56 \\
10(17 \cdot 9)\end{array}$ & $\begin{array}{l}421 \\
80(19 \cdot 0)\end{array}$ \\
\hline $\begin{array}{l}\text { Other: } \\
\text { All } \\
\text { Clinical diagnosis }\end{array}$ & $\begin{array}{l}65 \\
10(15 \cdot 4)\end{array}$ & $\begin{array}{l}72 \\
11(15 \cdot 3)\end{array}$ & $\begin{array}{l}55 \\
3(5 \cdot 5)\end{array}$ & $\begin{array}{l}192 \\
24(12 \cdot 5)\end{array}$ \\
\hline $\begin{array}{l}\text { Total: } \\
\text { All } \\
\text { Clinical diagnosis }\end{array}$ & $\begin{array}{l}754 \\
146(19 \cdot 4)\end{array}$ & $\begin{array}{l}829 \\
132(15 \cdot 9)\end{array}$ & $\begin{array}{l}351 \\
37(10 \cdot 5)\end{array}$ & $\begin{array}{l}1934 \\
315(16 \cdot 3)\end{array}$ \\
\hline
\end{tabular}

Total 60's v 70's $v$ 80's $\chi^{2}=10 \cdot 16 ; \mathrm{p}<0.005$.

Medical/chest department 60's $v 70$ 's $v 80$ 's $\chi^{2}=7.45$; $\mathrm{p}<0.01$.

Medical $v$ surgical NS.

Medical $v$ other NS.

Surgical $v$ other NS.

Table 6 Percentage of clinically diagnosed cases of pulmonary embolism differentiating between pulmonary embolism as immediate (I) or contributing (II) cause of death

\begin{tabular}{|c|c|c|c|c|}
\hline \multirow[b]{2}{*}{ Cause } & \multicolumn{4}{|c|}{ Pulmonary embolism } \\
\hline & $\begin{array}{l}1960-69 \\
n(\%)\end{array}$ & $\begin{array}{l}1970-79 \\
n(\%)\end{array}$ & $\begin{array}{l}1980-84 \\
n(\%)\end{array}$ & $\begin{array}{l}\text { Total } \\
n(\%)\end{array}$ \\
\hline $\begin{array}{l}\text { Immediate (I): } \\
\text { All } \\
\text { Clinical diagnosis }\end{array}$ & $\begin{array}{l}547 \\
121(22 \cdot 1)\end{array}$ & $\begin{array}{l}664 \\
116(17 \cdot 5)\end{array}$ & $\begin{array}{l}239 \\
30(12 \cdot 6)\end{array}$ & $\begin{array}{l}1450 \\
267(18 \cdot 4)\end{array}$ \\
\hline All & $\begin{array}{l}207 \\
25(12 \cdot 1)\end{array}$ & $\begin{array}{l}165 \\
16(9 \cdot 7)\end{array}$ & 112 & $\begin{array}{l}484 \\
48(9.9)\end{array}$ \\
\hline
\end{tabular}

I: 60's $v 70$ 's $v 80$ 's $\chi^{2}=7.58 ; \mathrm{p}<0.01$.

II: 60's $v 70$ 's $v 80$ 's: NS.

Total: I $v$ II $\chi^{2}=14.37 \mathrm{p}<0.0005$.

ences were found between departments as a whole.

When pulmonary embolism is the immediate cause of death clinical detection was better than when it was considered to be a contributory cause at necropsy (table 6). The ratio of immediate to contributory cause was similar over the period studied, but a significant decrease in the incidence of clinically diagnosed pulmonary embolism as the immediate cause of death was seen (table 6). When heart disease and cancer were the underlying cause of death, the clinical diagnosis seemed to be made more frequently in connection with heart disease (table 7).

\section{Discussion}

The clinical diagnosis of pulmonary embolism was more accurate in this hospital 25 years ago than currently, and this is most obvious in patients with heart disease and cancer, and in cases with pulmonary 
Table 7 Cases in which clinical diagnosis of pulmonary embolism was missed, related to underlying disease

\begin{tabular}{|c|c|c|c|c|}
\hline \multirow[b]{2}{*}{ Underlying diseases } & \multicolumn{4}{|c|}{ Pulmonary embolism } \\
\hline & $\begin{array}{l}1960-69 \\
n(\%)\end{array}$ & $\begin{array}{l}1970-79 \\
n(\%)\end{array}$ & $\begin{array}{l}1980-84 \\
n(\%)\end{array}$ & $\begin{array}{l}\text { Total } \\
n(\%)\end{array}$ \\
\hline $\begin{array}{l}\text { Heart: } \\
\text { All } \\
\text { Clinical diagnosis } \\
\text { Stroke: } \\
\text { All } \\
\text { Clinical diagnosis } \\
\text { Pulmonary embolism (sole): } \\
\text { All } \\
\text { Clinical diagnosis } \\
\text { Cancer: } \\
\text { All } \\
\text { Clinical diagnosis } \\
\text { Other: } \\
\text { All } \\
\text { Clinical diagnosis }\end{array}$ & $\begin{array}{l}270 \\
68(25 \cdot 2) \\
125 \\
13(10 \cdot 4) \\
14 \\
3(21 \cdot 4) \\
184 \\
33(17 \cdot 9) \\
161 \\
29(18 \cdot 0)\end{array}$ & $\begin{array}{l}259 \\
48(18.5) \\
123 \\
17(13 \cdot 8) \\
25 \\
4(16.0) \\
258 \\
32(12.4) \\
164 \\
31(18.9)\end{array}$ & $\begin{array}{l}106 \\
12(11 \cdot 3) \\
42 \\
5(11 \cdot 9) \\
28 \\
1(3 \cdot 6) \\
127 \\
11(8 \cdot 7) \\
48 \\
8(16 \cdot 7)\end{array}$ & $\begin{array}{l}635 \\
128(20 \cdot 2) \\
290 \\
35(12 \cdot 1) \\
67 \\
8(11 \cdot 9) \\
569 \\
76(13 \cdot 4) \\
373 \\
68(18 \cdot 2)\end{array}$ \\
\hline
\end{tabular}

Heart: 60's $v 70$ 's $v 80$ 's $\chi^{2}=6.68 ; \mathrm{p}<0.01$.

Cancer: 60's $v$ 70's $v 80$ 's $\chi^{2}=4.53$; $\mathrm{p}<0.05$.

Cancer $v$ heart $\chi^{2}=7.03 ; \mathrm{p}<0.01$.

embolism as the sole cause of death. There was no such change with stroke and "other diseases". Pulmonary embolism also tended to be more accurately diagnosed in patients with heart disease than in those with cancer.

The incidence of pulmonary embolism in this study was within range of that found in other retrospective studies. ${ }^{38-10}$ Almost all the emboli were macroscopical findings, and as expected, ${ }^{469}$ occurred most often in the elderly. Many pulmonary emboli may have remained undetected using routine necropsy techniques, ${ }^{4}$ but the number can be presumed to have remained constant over the period investigated as necropsy routines were unchanged. Although prospective studies are preferable for elucidating the incidence and accuracy of clinical diagnosis of pulmonary embolism, ${ }^{4}$ the consistently high necropsy rate in this hospital and the size of the series justifies the use of this material for a retrospective study.

This study has shown that pulmonary embolism is more common in women: pulmonary embolism is associated with femoral-popliteal thrombosis, ${ }^{4}$ which occurs more often in women. ${ }^{\prime}$ More women than men were reported with pulmonary embolism by Havig, ${ }^{4}$ but this trend failed to show up as a separate risk factor on multiple regression analysis; ${ }^{4}$ other studies show no sex difference. ${ }^{3}$ As old age seems to be an important risk factor, ${ }^{4}$ the higher longevity among women may help to explain the difference seen in this study.

At present, we do not know why the incidence of pulmonary embolism as the "sole" cause of death has increased. It may be associated with rise in survival age in the population. ${ }^{14}$ One third of the patients died within 24 hours of admission. These patients will have had their pulmonary embolism outside the hospital and are thus probably of "medical" origin. Probably the same is true for the rest of this group, and we can only speculate as to the cause, but changes in life-style and less exercise could be influential factors. ${ }^{15}$

Only $10 \%$ of the cases of pulmonary embolism seen at necropsy in 1980-84 would have been registered in death statistics based on clinical certification, compared with $20 \%$ for $1960-69$. This is in keeping with the fact that pulmonary embolism is a very difficult clinical diagnosis to make. ${ }^{246816}$ The increase in the incidence of clinically undetected pulmonary embolism over the period studied, even in the cases where pulmonary embolism was considered at necropsy to be the main or immediate cause of death, suggests that this difficulty has not been resolved by modern diagnostic procedures. Clinical awareness of the possibility of pulmonary embolism and reliance on clinical acumen are essential for correct diagnosis.

Pulmonary embolism in surgical patients is more dramatic and easier to recognise. At the end of the seventies our surgical department took part in a multicentre trial of plasma expanders and heparin in the prophylaxis of fatal pulmonary embolism. ${ }^{17}$ They thus paid special attention to this problem, which could explain the decrease in the incidence of pulmonary embolism in the department between 1970 and 1984. It may also have influenced the level of clinical diagnosis, which in the surgical department, in contrast to the others, did not become less accurate with time.

The medical departments showed a significant decrease in the detection of pulmonary embolism. Although patients in medical departments are more likely to have diseases which complicate the diagnosis of pulmonary embolism ${ }^{6}$ such as heart attacks and stroke, this does not explain the decline in diagnosed cases. On the contrary, our data indicate that pulmon- 
ary embolism is better diagnosed in heart disease than in cancer. Deaths from cancer have, however, increased in this hospital ${ }^{18}$ to such an extent that this may in part explain the overall decrease in clinically diagnosed pulmonary embolism.

The medical and surgical departments are now more specialised than they were 25 years ago. At night wards are covered by less experienced doctors who may not be familiar with the case notes. As these doctors write the death certificates and requests for necropsy on the basis of the case notes, the clinical diagnosis of pulmonary embolism may be missed more often than if this were done by the experienced senior doctors.

Interest in the necropsy has declined. ${ }^{19}$ Even among pathologists ${ }^{20}$ interest in necropsy presentation seems to have lost out in the face of impressive modern diagnostic equipment and laboratory techniques. Even so there is no doubt that pulmonary embolism is most clearly seen at necropsy, and clinicians who regularly witness postmortem examinations may increase the rate of successful diagnosis of the condition. $^{21}$

Our thanks are due to Professor F Hartveit of this department for criticism of the manuscript, to Professor B Arnesjö and Dr A Horn of the surgical department, and Professor C O Solberg and Dr G von der Lippe of the medical department for their helpful comments.

\section{References}

1 Beckering RE, Titus JL. Femoral-poplital venous thrombosis and pulmonary embolism. Am J Clin Pathol 1969;52:530-7.

2 Dalen JE, Dexter L. Pulmonary embolism. JAMA 1969;207: 1505-7.

3 Dexter L, Dock DS, McGuire LB, et al. Pulmonary embolism. Med Clin North Am 1960;44:1251-68.

4 Havig Ø. Deep vein thrombosis and pulmonary embolism. Chapter IV: Pulmonary embolism. Acta Chir Scand 1977;(suppl 478):24-76.
5 Hellerstein HK, Martin JW. Incidence of thromboembolic lesions accompanying myocardial infarction. Am Heart $J$ 1947;33: 443-52.

6 Israel HL, Goldstein F. The varied clinical manifestation of pulmonary embolism. Ann Intern Med 1957;47:202-26.

7 Morell MT, Dunhill MS. The post-mortem incidence of pulmonary embolism in a hospital population. Br J Surg 1968; 55:347-52.

8 Parker BM, Smith JR. Pulmonary embolism and infarction. A review of the physiologic consequences of pulmonary arterial obstruction. Am J Med 1958;24:402-27.

9 Zimmerman LM, Miller D, Marchall AN. Pulmonary embolism. Its incidence, significance, and relation to antecedent vein disease. Surg Gyneol Obstet 1949;88:373-88.

10 McIntyre KM, Belko JS, Sasahara AA, et al. Pulmonary embolism. Premonitory signs and recurrence. After vena cava ligation. Archives of Invest Surgery 1969;98:671-3.

11 Freiman DG, Suyemoto J, Wessler S. Frequency of thromboembolism in man. $N$ Engl J Med 1965;272:1278-80.

12 Morrell MT, Truelove SC, Barr A. Pulmonary embolism. Br Med $J$ 1963;2:830-5.

13 Hartveit F. Necropsy findings in cases with clinically uncertain cancer diagnosis. J Pathol 1979;129:111-9.

14 Statistical Yearbook. Oslo: Central Bureau of Statistics of Norway 1984:63.

15 Wright IS. Pulmonary embolism: A most underdiagnosed and untreated disorder. J Am Geriat Soc 1974;22:433-9.

16 Coon WW, Coller FA. Clinicopathologic correlation in thromboembolism. Surg Gynecol Obstet 1959;109:259-69.

17 Gruber UF, Saldeen T, Brokop T, et al. Incidences of fatal postoperative pulmonary embolism after prophylaxis with dextran 70 and low-dose heparin: an international multicentre study. Br Med J 1980;10:1-9.

18 Hartveit F, Karwinski B. Changes in necropsy profile -1975 and 1984. J Pathol 1987;153:91-8.

19 Svendsen E, Hill RB. Autopsy legislation and practice in various countries. Arch Pathol Lab Med 1987;111:846-50.

20 Lundberg GD. Medicine without the necropsy. Arch Pathol Lab Med 1984;108:449-54.

21 Stevanovic G, Tucakovic G, Dotlic R, et al. Correlation of clinical diagnosis with necropsy findings. Hum Pathol 1986;17:1225-30.

Requests for reprints to: Dr E Svendsen, Department of Pathology, The Gade Institute, Haukeland Hospital, 5021 Bergen, Norway. 